\title{
Mental disorders in ecstasy users: a prospective-longitudinal investigation
}

\author{
Roselind Lieb ${ }^{\text {a }}$, Christian G. Schuetz ${ }^{\text {b }}$, Hildegard Pfister ${ }^{a}$, Kirsten von Sydow ${ }^{\text {a }}$, Hans- \\ Ulrich Wittchen ${ }^{\mathrm{a}, \mathrm{c}}$
}

\author{
a Clinical Psychology and Epidemiology Unit, Max Planck Institute of Psychiatry, Kraepelinstr. 2- \\ 10, 80804 Munich, Germany \\ b Department of Psychiatry, Ludwig Maximilians University, Nussbaumstr. 7, 80336 Munich, \\ Germany \\ c Institute of Clinical Psychology and Psychotherapy, Technical University of Dresden, \\ Chemnitzerstr. 46, 01187 Dresden, Germany
}

\begin{abstract}
Objectives: To investigate the relationship between ecstasy use and mental disorders in a representative sample of adolescents and young adults. Method: Data for this investigation were drawn from the Early Developmental Stages of Psychopathology (EDSP) study, an epidemiological-longitudinal study in which 14-24 year-olds were examined prospectively over a period of about 4 years. Results are based on $\mathrm{N}=2462$ participants who completed the whole study period and for whom drug use behavior could be determined. Results: (1) Ecstasy users, compared with non-users, were at significantly increased risk of DSM-IV substance related disorders, including alcohol use disorders (52.6 vs. 15.6\%; OR=5.6, 95\% CI=3.8-8.1). Further, ecstasy users also had a higher risk of alcohol use disorders, when compared with users of other illicit substances (52.6 vs. 40.3\%; OR=1.7, 95\% CI=1.1-2.4). (2) Ecstasy users had significantly higher rates for almost all DSM-IV mental disorders examined when compared with non-users (any nonsubstance use disorder: 68.7 vs. $44.5 \%$; $\mathrm{OR}=3.1,95 \% \mathrm{CI}=2.1-4.4$ ) and compared with users of other illicit drugs (any non substance use disorder: 68.7 vs. 55.5\%; OR=1.8, 95\% CI=1.2-2.6). (3) Ecstasy users also reported significantly higher rates of prescription medicine use, though they did not use more medical services than non-drug users. (4) Analyses of temporal patterns of ecstasy use and disorder onset revealed that the first use of ecstasy was secondary to the onset of DSM-IV mental disorders in the majority of cases. Still, subjects with mental disorders at baseline also showed a significantly increased risk for initiation of ecstasy use during the 4-year follow-up period. Conclusions: Care should be taken in cross sectional studies in interpreting mental disorder signs and symptoms merely as a consequence of ecstasy use, as ecstasy use might be associated with the use of multiple substances, and onset of mental disorder is more likely to precede rather than to follow use of ecstasy and related substances.
\end{abstract}

Keywords: Mental; Ecstasy user; Psychopathology; Epidemiology

\section{Introduction}

The World Health Organization (WHO) in 1996 acknowledged that 3,4-methylendioxy$\mathrm{N}$-methyl-amphetamin (MDMA), known as 'Ecstasy', and similar substances are becoming an established part of youth culture in some countries and that use is not generally perceived as dangerous (WHO, 1996). Epidemiological studies reveal that ecstasy use is common in the general population. A community survey of 3021 adolescents and young adults in the Munich (Germany) metropolitan area revealed in 1995 that $4 \%$ of the male and 2.3\% of the female respondents aged 14-24 had used 
ecstasy, in addition to $3.6 \%$ of men and $1.6 \%$ of women who had used ecstasy-related substances (chemically related compounds, including amphetamines) (Perkonigg et al., 1998a). This rate was at least a 2-fold increase, compared with findings from a 1990 survey (Schuster et al., 1998), suggesting a considerable elevation in incidence within the past decade.

Pharmacologically, ecstasy pills should contain MDMA. However, Galliot-Guilley et al. (1999) showed that the generic term 'ecstasy' actually covers a wide variety of molecules with variable formulations. Their findings suggest only $22 \%$ of ecstasy pills to contain any MDMA. Similar results have been reported by other groups. In fact, ecstasy pills often contain other stimulating substances including caffeine, amphetamine and amphetamine derivatives, e.g. designer drugs, such as 3,4-methylendioxy-N-ethyl-amphetamin (MDE), 3,4-methylendioxy-amphetamin (MDA) (Sherlock et al., 1999; Christophersen, 2000).

Originally, 'ecstasy' was considered a relatively benign substance (Chesher, 1990; Solowij et al., 1992). Recent reports, however, show that use of ecstasy and related compounds may be associated with problems similar to those experienced by users of cocaine, including dependence (Morgan, 1998; Jansen, 1999). In addition to its rewarding effects, ecstasy's psychological effects may include cognitive deficits, confusion, depression, sleep problems, anxiety, and paranoia, sometimes lasting weeks after discontinuation of ecstasy use (Krystal et al., 1992; Wodarz and Böning, 1993; Parrott et al., 1998). Physical effects of ecstasy use may include muscle tension, involuntary teethclenching, nausea, blurred vision, faintness, and increases in heart rate and blood pressure (Liester et al., 1992; Gouzoulis-Mayfrank and Hermle, 1994; Thomasius et al., 1997; Schütz and Soyka, 1998; Vollenweider et al., 1998).

It has been a commonly held belief that recreational ecstasy use was infrequent with intermittent oral administration of little health concern (Beck and Rosenbaum, 1994). Reports have not only questioned the benign 'pharmacological' nature of ecstasy, but also its context. In an Italian study, Schifano and colleagues (Schifano et al., 1998) examined 150 ecstasy users presenting to the Padova Addiction Treatment Unit between 1991 and 1996 and found ecstasy use to be highly associated and intertwined with an extensive use of other licit and illicit substances. Furthermore, extensive psychopathology was found in this sample, including depression (32\%), psychotic disorders (28\%), cognitive impairment (27\%), bulimia (24\%) and panic attacks (12\%). The authors concluded that psychopathology was substance induced but their findings are not generalizable to the community due to self-selection into treatment. Topp et al. (1999) found extensive polydrug use to be the norm among 329 ecstasy users in an Australian sample. Specifically, an average of eight physical and four psychological symptoms were attributed to ecstasy use within the last 6 months and one-fifth had sought professional help for a problem associated with ecstasy use. More recently, Pederson and Skrondal (1999) found that, among a sample of 10812 adolescents aged 14-17 years in Oslo, ecstasy use was initiated subsequent to already existing use of other illicit substances, indicating that it was introduced late in a hypothesized drug use sequence.

Epidemiological studies in unselected samples on the association between ecstasy use with DSM-IV mental disorders are lacking.

In sum, these findings suggest that use of ecstasy or related substances may be embedded in polydrug use and that use of ecstasy may be associated with significant mental problems and a wide range of mental disorders. However, results to date are limited in their generalizability to the community in at least two ways. First, previous studies are 
based solely on clinical samples. Therefore, it is not known whether the observed associations between ecstasy use and mental disorders exist among those who use ecstasy and do not seek help. Second, previous studies are cross-sectional. Therefore, it cannot be determined whether mental disorders precede or follow the initiation of ecstasy use. The current study allows us to fill this gap by using a prospective-longitudinal design to examine the relationship between ecstasy use and mental disorders among a representative sample of more than 3000 adolescents and young adults in the community.

The aims of this paper are 3-fold: (1) to evaluate the co-occurrence of ecstasy and related illicit drug use and DSM-IV mental disorders in a representative community sample of adolescents and young adults, unbiased by treatment selection or self referral; (2) to investigate the association between ecstasy use and utilization of medical and psychological services, as well as prescription medication use; (3) to examine whether use of ecstasy and related compounds precedes or follows the onset of mental disorders.

\section{Methods}

\subsection{Design}

The Early Developmental Stages of Psychopathology study (EDSP) is a prospectivelongitudinal design based on a representative community sample of adolescents and young adults living in the Munich area, aged 14-24 years at baseline. The EDSP consists of a baseline investigation (T0), two follow-up investigations (T1, T2) and an independent parent survey. Detailed descriptions of the design have been presented elsewhere (see Wittchen et al., 1998a; Lieb et al., 2000).

\subsection{Sample}

The EDSP sample was drawn randomly from the 1994 government population registries of residents in metropolitan Munich and the surrounding counties with an expected age range for the sampled subjects between 14 and 24 at the time of the baseline interview in 1995. As the study was designed as a longitudinal panel with special interest in early developmental stages of psychopathology, 14-15 year-olds were sampled at twice the probability of people 16-21 years of age, and 22-24 year-olds were sampled at half the probability of the 16-21 year-olds. From the total of 4809 sampled individuals, 4263 were located and determined to be eligible for the study. Sampled individuals who were not located were disproportionately older. In comparison to located subjects, subjects who could not be located had either moved outside the metropolitan Munich area in the time interval between their registration and the beginning of the study in 1995 (8.8\%) or could not be assessed with the listed address during the field work period (2.4\%). From the 4263 individuals a total of 3021 interviews were completed at baseline (T0) resulting in a response rate of $71 \%$. Refusal to participate $(18.2 \%)$ was by far the most frequent reason for non-response, followed by a reported lack of time (3.3\%), failure to contact anyone in the identified household (3.1\%), and failure to contact the sampled individual in the household (3.0\%). The demographic distribution of the sampled population and the respondents has been reported elsewhere (Wittchen et al., 1998a,b). Briefly, at baseline almost three-quarters of the population were students, 36\% at the secondary level and $35 \%$ at university. Nearly twothirds (64\%) of the sample were living with their parents and $23 \%$ were living alone. Two follow-up investigations (T1+T2) were completed after the initial baseline assessment, covering an overall period of 42 months (range: 34-50 months). 
The first follow-up (T1) was conducted in 1996/1997 and was confined to the younger subsample (aged 14-17 years at baseline); 1228 interviews were completed, giving a follow-up response rate of $88 \%$. The second follow-up (T2) included all baseline respondents and was conducted in 1998-99, an average of 42 months after the baseline investigation (range 34-50 months); the response rate was $84 \%$. Drug use behavior could be determined in at least one of the assessment stages for 2462 participants. Noteworthy changes in sociodemographic characteristics from baseline to second followup were found only for school/employment status (T2: secondary school: 13\%; employed: $36 \%$ ) and living arrangements (with parents: 40\%; with partner: 23\%). At second follow-up, the most frequent reasons for nonresponse were refusal to participate $(9.2 \%)$, failure to contact the individual (2.7\%) and lack of time (1.5\%).

\subsection{Measures}

\subsubsection{Diagnostic assessment}

Face-to-face computer assisted interviews were administered by a highly experienced survey staff consisting of 57 clinical interviewers, most of whom were clinical psychologists who had extensive experience in diagnostic interviewing including the computer assisted version of the Munich-Composite International Diagnostic Interview (M-CIDI; Wittchen and Pfister, 1997). At baseline, 25 professional health research interviewers recruited from a survey company were additionally involved. Formal training with the M-CIDI took place for 2 weeks, followed by at least ten closely monitored practice interviews and additional 1-day booster sessions throughout the study.

The M-CIDI is an updated version of the WHO's CIDI version 1.2 (WHO, 1990) that incorporates questions assessing DSM-IV (APA, 1994) and ICD-10 (WHO, 1994) criteria. The M-CIDI allows for the standardized assessment of symptoms, syndromes and diagnoses of a wide range of DSM-IV substance use and mental disorders (and additionally various subtypes of main disorders) along with information about onset, duration, and clinical and psychosocial severity. In the baseline investigation, the lifetime version of the M-CIDI was used to assess lifetime and 12-month information. For the two follow-up investigations, the M-CIDI was modified to cover the 12-month period prior to the follow-up interview as well as the remaining interval between the investigations (12month-interval-version). In all assessments the M-CIDI was supplemented by a separate, individual booklet for each respondent that included several scales and questionnaires for assessing psychological constructs that are relevant to our study. A detailed overview and characterization of the constructs and assessment scales used has been presented elsewhere (Wittchen et al., 1999; Höfler et al., 1999; Lieb et al., 2000). The reliability and validity of the M-CIDI have been established and reported in greater detail elsewhere (Lachner et al., 1998; Reed et al., 1998; Wittchen et al., 1998c).

In all three waves, individuals were contacted first by letter and subsequently by telephone to arrange a meeting. Most interviews (including the assessments of questionnaires) took place in the homes of the respondents or, in some instances, at another location preferred by the respondents. Participants provided informed consent.

\subsubsection{Assessment of drug use}


The section of the face-to-face M-CIDI which assesses illicit drug use has already been described in detail in previous publications (Lachner et al., 1998; Perkonigg et al., 1998b; Schuster et al., 1998). Therefore, only a brief summary will be given here. In the initial screening part of the drug section, the respondent is first asked whether he or she is willing to respond to these questions openly ('commitment probe'). Only very few (less than $1 \%$ of the sample) denied this question; in these cases the complete substance section was skipped. The section continues with a comprehensive list of eight types of substances (e.g. cannabis, opioids) along with the most frequent market and street names. The respondent is asked whether he or she has ever taken one of the presented substances. Whenever the respondent acknowledged having used at least one of the substances on at least five occasions, the section continued with a further assessment of quantity and frequency of use as well as associated abuse or dependence symptoms. In addition to the drugs from the list, the respondent is free to add any other substance. In determining ecstasy use, the wide range of names used for it and the user's lack of precise knowledge about the chemically active ingredients make accurate assessment difficult. Simply inquiry about 'ecstasy' use might lead to an underestimate. Therefore, we assessed not only respondents capable of making reasonably clear indications about specifically using ecstasy but also those using other terms or other types of stimulants likely to be ecstasyrelated drugs (such as MDE, MDA, and also including amphetamines or speed). All subjects having used a drug at least five times ever are then interviewed with the full diagnostic section to establish the presence or absence of all DSMIV diagnostic criteria for abuse or dependence.

\subsection{Assessment of indicators of medical complications}

At second follow-up (an average of 42 month later), indicators of medical complications were assessed by evaluating respondents' recent use of health services as well as current intake of medications. Assessment of health service utilization was determined by asking whether and how often they went to see any of the professionals presented on a separate list (e.g. psychiatrist, internist) during the past 12 months. Current medication use was assessed by asking respondents if they had used any of the medications presented on a list (e.g. pain killers) during the last 4 weeks.

\subsection{Analysis of the data}

Based on the respondents information given in the different waves for the drug use section, this paper divides the sample into three mutually exclusive groups according to their lifetime drug use status at second follow-up: (1) ecstasy and related drugs: this group includes all respondents who reported at either baseline or the follow-up assessments at least one intake of ecstasy or any ecstasy-related drug, (2) other illicit drugs: this group includes all respondents who used at least once in their life any illicit drug (e.g. cannabis, cocaine, opioids), but never used ecstasy or any ecstasy-related drug, and (3) no illicit drug: this group includes all respondents who reported neither use of any illicit drugs at baseline nor at the follow-up assessments. Cumulative lifetime incidences of DSM-IV mental disorders, which were calculated by adding baseline (T0) and follow-up (T1, T2) incident cases, were used for the analyses of lifetime co-morbidities between DSM-IV mental disorders and use of ecstasy and related drugs. Here, odds ratios (ORs) were calculated as measures of strength of associations. All associations were adjusted for age, gender and socio-demographic effects (McCullagh and Nelder, 1989). In order to exclude the possibility that positive associations are artifactual because the younger cohort has been assessed three times, all calculations were tested for an interaction effect with age 
cohort and in case of significance were run separately within each cohort. In terms of temporal patterns of comorbidity, use of ecstasy and related drugs was termed as 'temporally primary' whenever their age of first use preceded the age of onset of the comorbid DSM-IV mental disorder. Conversely, when the age of first use occurred after the age of onset of the comorbid disorder, use of ecstasy and related drugs was said to be 'temporally secondary'.

To account for the different sampling probabilities, non-contact and non-response, a relative weight was used in all analyses that adjusts the data by age, sex and geographic location to match the distribution of the sampling frame. A more detailed description of the EDSP weighting procedure is presented elsewhere (Wittchen et al., 1998a; Lieb et al., 2000).

All statistical analyses were performed using the software package STATA (Stata Corp., 1999), which applies the Huber-White sandwich matrix for robust estimates of standard errors and confidence intervals in the case of weighted data (Royall, 1986). The present analyses are based on the data for the respondents who completed the whole 4-year study period and for whom drug use behavior could be determined ( $\mathrm{N}=2462 ; 97 \%$ of the final follow-up sample). Subjects for whom lifetime ecstasy use could not be determined were excluded from the analyses $(\mathrm{N}=86)$.

\section{Results}

\subsection{Estimated cumulative lifetime use of ecstasy and other illicit substances}

A total of 211 respondents (8.9\%; percentages are adjusted by weights for sampling design) reported having used either ecstasy (6.6\%) or any ecstasy-related substance including amphetamine (2.3\%) at least once in their lifetime. Males reported use of ecstasy more frequently than females (10.4 vs. $7.5 \%$; OR=1.4; 95\% CI=1.0-2.0).

Almost 40\% (39.7\%) of the sample used illicit substances other than ecstasy, amphetamine or related compounds at least once, with higher rates in males than females (44.8 vs. 34.7\%; OR=1.5; 95\% CI=1.3-1.8). No differences in drug use rates were found between the younger (the 14-17 year-olds at baseline) and the older (18-24 year-olds at baseline) age groups. Fig. 1 shows the age-specific cumulative incidences for use of ecstasy and related substances in males and females.

\subsection{Socio-demographic correlates}

At baseline, only few socio-demographic characteristics were found between respondent who had and had not used ecstasy (results not shown but available on request). Higher education (Gymnasium, a secondary education, which prepares students for University) was found to be associated with a decreased likelihood of using ecstasy, when ecstasy users were compared with respondents who never used illicit substances. There was no significant difference in socio-demographics from the baseline assessment comparing ecstasy users and users of other illicit substances.

When these analyses were re-run using socio-demographics from the second follow-up investigation (controlling for age and gender), results differed (Table 1). University level education was significantly associated with lower ecstasy use, when comparing ecstasy users both to non-users and to users of other illicit substances. In addition, being 
unemployed and being from a lower social class (self-attributed) was associated with increased risk of ecstasy use, in comparison both to nonusers and users of other illicit substances. Comparing users of ecstasy to non-drug users, increased risk of use was further significantly associated with living alone and not being married, especially if separated, divorced or widowed.

Having established a number of significant associations of ecstasy use and sociodemographic factors, we estimated ORs controlled for possible confounders: age, gender, education living arrangements, and financial situation. Controlled ORs and OR not controlled for these variables showed no more than marginal differences, thus we report results based on controlled ORs only.

\subsection{Associations with substance use and substance use disorder}

As presented in Table 2, the majority of respondents (68.7\%) who ever used ecstasy reported a history of at least one DSM-IV mental disorder. Users of ecstasy and related compounds also reported higher proportions of alcohol use disorders (52.6 vs.15.6\%; $\mathrm{OR}=5.6)$ and nicotine dependence (53.2 vs. $10.4 \%$; $\mathrm{OR}=9.9$ ) than respondents who never used illicit substances. Users of ecstasy and related compounds were also found to reveal higher proportions when compared with users of other illicit substances: alcohol use disorders (52.0 vs. 40.3\%; OR=1.7) and nicotine dependence (53.2 vs. 37.1\%; OR=1.8). A comparison of abuse and dependence diagnoses in both substance using groups indicates that use of illicit substances is considerably higher in ecstasy users (43.7 vs. 11.7\%; $\mathrm{OR}=6.4)$. Further, almost all users of ecstasy and related compounds (93\%) also reported the use of cannabis. Proportions for concommittant cannabis use were similarly high in other illicit drug users (95\%). Opioids had been used by 3.9\% of the users of illicit substances with no experience with ecstasy, while $21.4 \%$ of the ecstasy users reported experience with opioids. Similarly, $6.5 \%$ of the users of illicit substances with no experience with ecstasy had used cocaine, while $59.1 \%$ of those with a history of ecstasy use reported experience with cocaine (Results not shown, but available on request).

\subsection{Associations with mental disorders}

When investigating DSM-IV non-substance mental disorders among ecstasy users, increased proportions were found as compared with non-users for most mental disorders, including affective disorders $(\mathrm{OR}=2.6)$, anxiety disorders $(\mathrm{OR}=2.4)$, somatoform disorders $(\mathrm{OR}=1.8)$, and eating disorders $(\mathrm{OR}=3.6)$. Most of these associations remain statistically significant (or close to being statistically significant) when associations of users of ecstasy and related substances were compared with those using other illicit substances (but not ecstasy), yet the associations appear to be less pronounced.

Suicidal ideation was significantly more often reported by users of ecstasy and related compounds than by respondents without any use of illicit substances $(\mathrm{OR}=2.2)$.

All analyses were examined to detect cohort effects between the younger cohort (age 1417 at baseline) and the older cohort (age 18-24 at baseline). Among the large number of interactions investigated a total of four significant findings could be detected: alcohol abuse and bipolar I disorder had higher ORs in the younger cohort. Any somatoform disorder and especially pain disorder had higher ORs in the older cohort. Given the small number and unsystematic character of interactions between these two cohorts, we conclude that no systematic cohort effect could be detected. 


\subsection{Health care utilization}

Although ecstasy users reported slightly higher proportions of primary care and specialist medical services only one comparison was significant (Table 3). Users of ecstasy and related compounds more often sought the help of psychologists $(\mathrm{OR}=2.3)$.

Table 3 also reveals higher proportions of use of prescription medications of users of ecstasy compared with respondents who never used illicit substances, especially for use of pain killers $(\mathrm{OR}=1.9)$, sleeping pills $(\mathrm{OR}=4.2)$, sedatives $(\mathrm{OR}=2.3)$, psychotropics $(\mathrm{OR}=9.0)$ and stimulants $(\mathrm{OR}=6.7)$. No significant differences in use of other medications were found, except for vitamins $(\mathrm{OR}=1.5)$. Comparisons of users of ecstasy and related compounds and users of other illicit substances again revealed significantly increased use rates for pain killers $(\mathrm{OR}=1.6)$, sleeping pills $(\mathrm{OR}=2.2)$, psychotropics $(\mathrm{OR}=3.3)$ and stimulants $(\mathrm{OR}=4.9)$. No age cohort effect was detected.

\subsection{Temporal sequence in onset of ecstasy use and DSM-IV mental disorders}

Table 4 summarizes temporal sequence of onset of ecstasy use and DSM-IV mental disorders. Overall, the onset of mental disorders clearly occurred prior to the first use of ecstasy in the large majority (88.4\%) of cases. This pattern persists even if other substance related disorders are excluded from the analysis of ecstasy use and onset of mental disorders (80.4\%). The most frequent mental disorders occurring prior to the onset of the first use of ecstasy were: specific phobia (98.4\%), social phobia (76.6\%), alcohol abuse/dependence (78\%) and somatoform conditions (73.2\%). In a smaller percentage of cases, the onset of mental disorders occurred subsequent to the initiation of ecstasy use. Most frequent secondary mental disorders following onset of ecstasy use were: major depression (40\%), phobia NOS (29.8\%), panic disorder (22.9\%), agoraphobia (25.7\%), generalized anxiety disorder (25.3\%) and eating disorder (28.5\%). In order to investigate the temporal pattern of onset with a more rigorous statistical approach, we selected subjects with and without ecstasy use at T0 and compared the number who developed mental disorders. We found no significant difference in the incidence of mental disorders between these two groups ( $\mathrm{OR}=2.9 ; 95 \% \mathrm{CI}=0.8-9.7)$, despite the elevated point estimate among those with ecstasy use at T0 (57.2 vs. 36.4\%). This may be due to small cell size $(\mathrm{N}=13, \mathrm{Nw}=17)$. Comparing patterns of incidence of ecstasy use among those with, compared with those without, a history of mental disorder at T0, we found a significant difference $(\mathrm{OR}=2.6,95 \% \mathrm{CI}=1.7-4.1)$ with a higher point estimate of ecstasy use among those with a history of mental disorder (6.0\%) compared with those with no mental disorder (3.2\%).

\section{Discussion}

Based on a 4-year prospective longitudinal (-) community study of 3021 subjects aged 1424 at baseline the present paper confirmed earlier findings (Perkonigg et al., 1999;

Schuster et al., 1998; Sydow et al., 2002), that the use of ecstasy and related substances is widespread in the community. Thus, at time in point of the second follow-up investigation, we observed a cumulative lifetime incidence rate of ecstasy use of $8.9 \%$ (males, 10.4\%; females, $7.5 \%$ ) of the total sample. The use of a prospective-longitudinal design with an unselected community sample, and comprehensive standardized substance use-related and psychopathological assessments, offers the opportunity to study the 
predictors, correlates and consequences of ecstasy use with findings that are generalizable to the community.

The overall findings from the study confirm that ecstasy use constitutes a complex and multifaceted phenomenon in our sample. Several findings should be highlighted:

1) The study supports recent findings that the majority of ecstasy users are polydrug users as well; 53\% fulfill criteria for nicotine dependence, $44 \%$ meet criteria for any illicit substance use disorder (abuse: 34\%, dependence: 22\%) and 53\% meet criteria for an alcohol use disorder. Thus, users of ecstasy and related compounds are at a moderately increased risk for abuse of and dependence on licit drugs, compared to those without ecstasy use, and a more pronounced risk for abuse and dependence of illicit drugs, compared to those who have not used ecstasy. This finding is not surprising when the comparison group consists of subjects with no experience in using any illicit substance, but also persists even when users of ecstasy and related substances were compared with illicit drug users. The excessive use of prescription medicines among ecstasy users, in particular pain killers, sedatives, sleeping pills, and other prescribed psychotropics, should also be emphasized especially in view of the fact that they did not report increased rates of health service utilization, with the exception of more visits to psychologists. This might indicate that ecstasy users are more likely than people with no drug use to misuse prescription drugs.

2) It is also noteworthy that socio-demographic factors at baseline do not appear to predict first use of ecstasy at baseline in this sample. However, at follow-up we found several significant associations between demographic factors and ecstasy use. These included poorer educational status, lower social class, unemployment and being separated, divorced, or widowed. This finding might signal that these socio-demographic factors are more likely to be a correlate or consequence of ecstasy use than a causal risk factor for initiation. That the sociodemographic correlates of other drug use (e.g. cannabis) resembled those of ecstasy use but again did not predict it at baseline offers additional evidence in support of this tentative conclusion.

3) The study's primary aim was to investigate the association between use of ecstasy and related substances and the risk of non-substance-related mental disorders. Ecstasy use was associated with a substantially increased risk for almost all mental disorders examined. Specifically, 69\% had at least one mental disorder. In comparison to non drug users, the odds of having a mental disorder was 3- fold among ecstasy users, compared with non users, and almost 2-fold, compared with users of other illicit substances. Ecstasy use was also strongly associated with having two or more lifetime mental disorders in comparison to both reference groups. In detail, $51 \%$ of all ecstasy users had a current or past diagnosis of anxiety disorders, $43 \%$ of somatoform disorders, and $40 \%$ of any affective disorder. Compared with non-drug users and other illicit substance users the strongest associations were between ecstasy use and panic attacks and panic disorder, general anxiety disorder (GAD), posttraumatic stress disorder (PTSD), eating disorders and major depression.

4) Using the available longitudinal data, the examination of the temporal relationship between initiation of ecstasy use and onset of DSM-IV mental disorders was approached by two strategies. In the first set of analyses, we simply compared ages of onset of ecstasy use and age of onset of mental disorders. Results of this comparison suggest that the onset of DSM-IV mental disorders clearly precedes the onset of first ecstasy use in the majority of cases. Among those with mental disorders and ecstasy use, most frequently phobias 
(98-55\%, depending on type of phobic disorder), somatoform disorders and syndromes (73\%), dysthymia (69\%), and disorders of the panic/agoraphobic spectrum (61-63\%) preceded the onset of ecstasy use. It is also noteworthy, however, that mental disorders did not precede initiation of ecstasy use in all cases. In fact, ecstasy users were also found to develop mental disorders after first use of ecstasy had occurred. The most common secondary mental disorders were major depression (40\%), panic/agoraphobia/phobia NOS disorders (30-23\%), generalized anxiety and eating disorders. Further, the proportion (26\%) of those developing secondary illicit drug abuse or dependence is also noteworthy. We then performed a two-step second set of analyses toward this end, using a more complex statistical approach, due to the complex nature of the temporal relationship between onset of mental disorders and initiation of ecstasy use. The findings resulting from this methodological approach were consistent with and added greater depth to the findings of our initial analyses. First, with a prospective analysis of the data, we confirmed that subjects with a mental disorder at baseline were indeed more likely to begin using ecstasy, compared with subjects not diagnosed with a mental disorder at baseline. Second, we found that there was a higher incidence of mental disorders during follow-up among those with compared to those without ecstasy use at baseline, although this finding failed to reach statistical significance.

To conclude, despite the fact that there is a complex and powerful relationship between ecstasy use and mental disorders, these findings highlight that caution should be advised in assigning an overly specific causal role for ecstasy as a primary risk factor for the onset of mental disorders, even though neuroscientific findings provide quite plausible explanations for such a mechanism. Our results corroborate the finding that ecstasy users are characterized by very high levels of DSM-IV mental disorders and psychological problems. The strong association can be explained in a number of ways. Two basic causal pathways can be assumed: (1) mental disorders lead to substance use, e.g. in the form of 'self-medication', or (2) mental disorders are a consequence of substance use. Previous cross-sectional studies have argued consistently for the second option, based on contemporaneous reports that ecstasy seems to induce persistent neurological changes. Related to this, research has indicated that MDMA use may damage brain serotonin neurons (Ricaurte et al., 1985, 1988), which may play a role in mediating behavior disturbances and might lead to mental disorders (Allan et al., 1993; McCann et al., 1994; Scheffel et al., 1998; Sprague et al., 1998; Vollenweider et al., 1998; Ricaurte et al., 2000; McCann et al., 2000). According to this approach, ecstasy-induced psychopathology seems to be pharmacologically plausible. However, our findings which are based for the first time on a representative prospective-longitudinal sample support strong evidence for the first pathway, i.e. that mental disorders lead to the use of ecstasy, as the more dominant picture of our results suggests that subjects with existing anxiety, somatoform and depressive disorders are at high risk for ecstasy use and the development of other licit and illicit substance use disorders.

Limitations: These findings are based on a representative sample of the general population in Munich, Germany. It should be noted, however, that while these findings are consistent with the only previous population based study on ecstasy use and comorbidity (Pederson and Skrondal, 1999), their generalizability to demographically diverse populations may be limited. Therefore, these findings need replication in other population-based samples. While the study was prospective in nature, use of substances prior to baseline interview was necessarily retrospective and may, therefore, be subject to recall bias. We used DSMIV diagnoses, therefore, comparison of these findings to results of studies that use different psychiatric nosological classification systems are cautioned. Finally, we 
summarized ecstasy and ecstasy-related substance use in these analyses. While we found no significant differences between those who reported use of ecstasy and ecstasy-like substances, this methodology should be noted when comparing our findings with others.

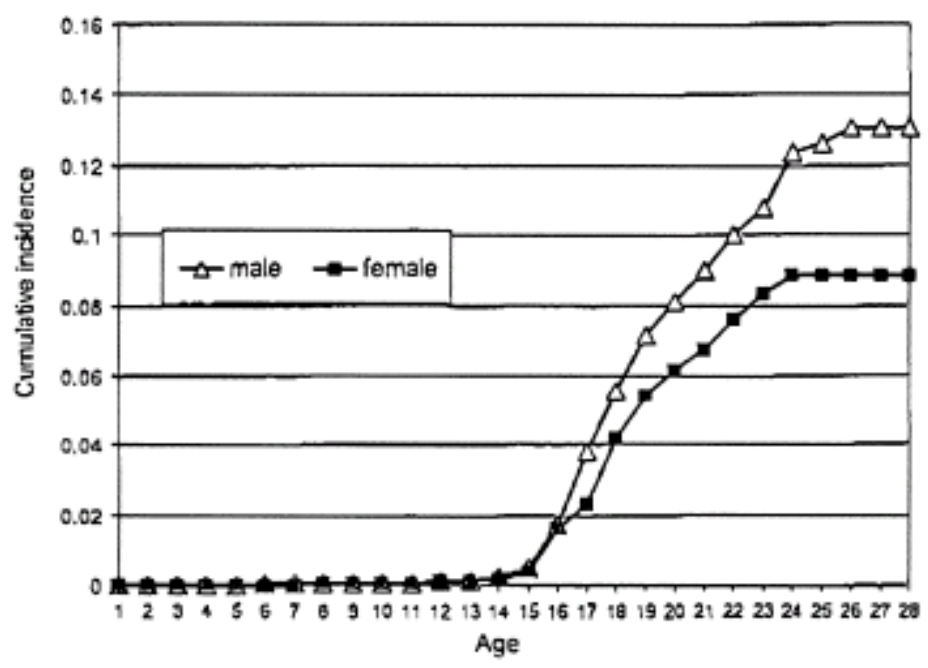

Fig. 1. Age of onset of use of ecstasy and related drugs by gender.

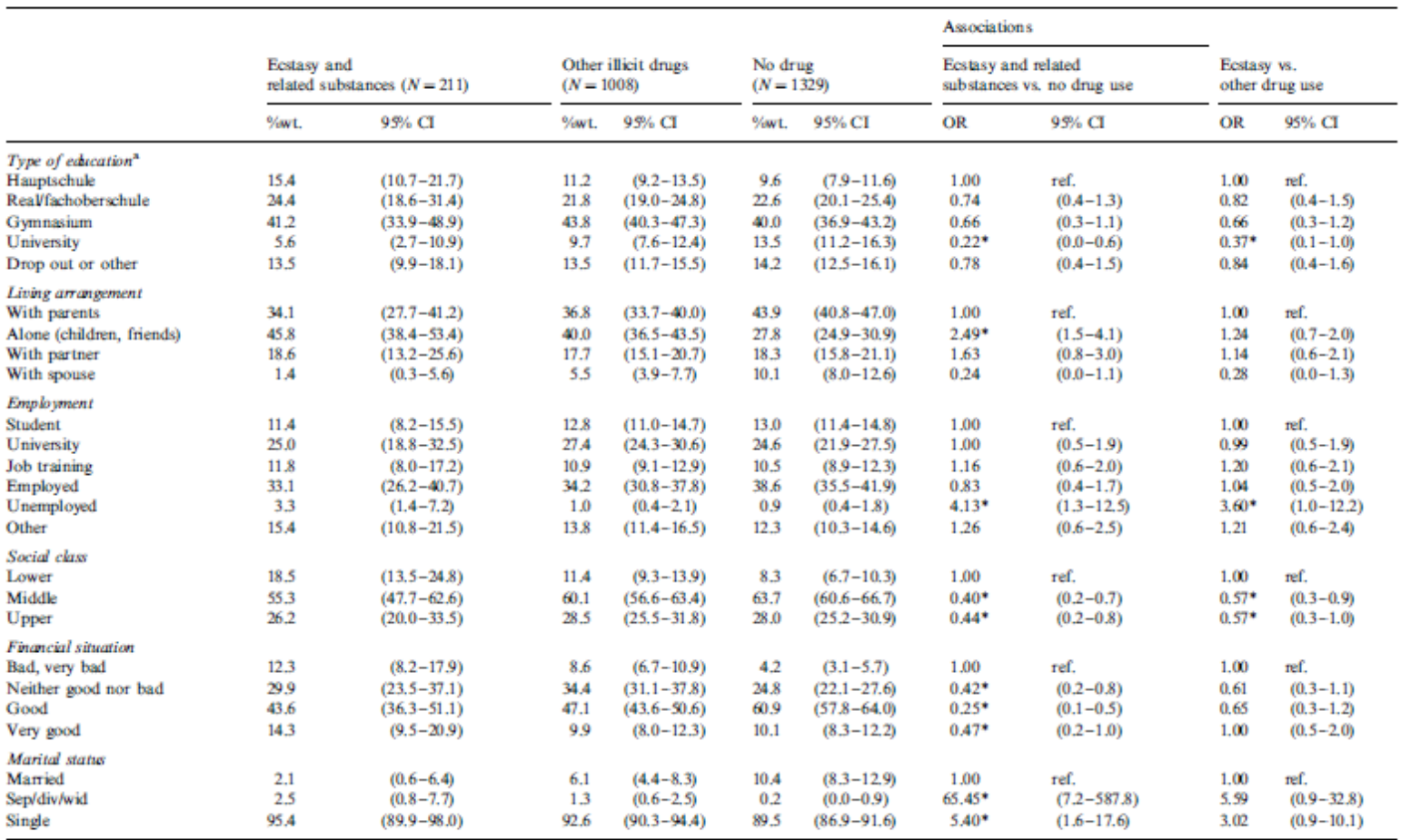

Percentages are computed in within the col umn tot als $N$ indicates unweighted number of subjects; \% wL. indicates weighted percentage of subjects OR indicates odds ratios Clindicates confidenee interval; all $\mathrm{ORs}$ are controlled for age and gender of subjects; $*, P<0.05$.

${ }^{a}$ Hauptschule, mandatory basic school; Rea/Tachoberschule, an intermediate type of advanced school between Hauptschule and Gymnasium; Gymnasium, secondary education between ages 10 and 19 , which prepares students for entrance to university. 


\begin{tabular}{|c|c|c|c|c|c|c|c|c|c|c|}
\hline \multirow[b]{3}{*}{ DSM-IV Disorder } & \multirow{2}{*}{\multicolumn{2}{|c|}{$\begin{array}{l}\text { Eestasy and related drugs } \\
(N=211)\end{array}$}} & \multirow{2}{*}{\multicolumn{2}{|c|}{$\begin{array}{l}\text { Other illicit drugs } \\
(N=1008)\end{array}$}} & \multirow{2}{*}{\multicolumn{2}{|c|}{$\begin{array}{l}\text { No drug } \\
(N=1329)\end{array}$}} & \multicolumn{2}{|c|}{ Associations } & \multirow{2}{*}{\multicolumn{2}{|c|}{$\begin{array}{l}\text { Eestasy and related drugg } \\
\text { vs other illikit drugs }\end{array}$}} \\
\hline & & & & & & & \multicolumn{2}{|c|}{$\begin{array}{l}\text { Eestasy and related } \\
\text { drugs vs, no drug }\end{array}$} & & \\
\hline & $\% w t$. & $99 \%$ C & \%wt. & $95 \% \mathrm{CI}$ & \%wt. & $95 \% \mathrm{CI}$ & $\mathrm{OR}^{\mathrm{x}}$ & $95 \% \mathrm{CI}$ & $\mathrm{OR}^{\mathrm{x}}$ & $99 \% \mathrm{CI}$ \\
\hline \multicolumn{11}{|l|}{ Substance use disorders } \\
\hline Alcohol abuse & 32.1 & $(25.6-39.4)$ & 30.8 & $(27.7-34.0)$ & 13.7 & $(11.6-16.0)$ & $2.68^{*}$ & $(1.8-4.0)$ & 1.03 & $(0.7-1.5)$ \\
\hline Alcohol dependence & 27.5 & $(21.2-34.8)$ & 13.4 & $(11.2-16,0)$ & 3.0 & $(2.0-4.3)$ & $10.57^{*}$ & $(6.0-18.5)$ & $2.58^{*}$ & $(1.6-4.0)$ \\
\hline Any alcohol use disorder & 52.6 & $(45.1-99.9)$ & 40.3 & $(37.0-43.7)$ & 15.6 & $(13.4-18.1)$ & $5.58^{*}$ & $(3.8-8.1)$ & $1.67^{*}$ & $(1.1-2.4)$ \\
\hline Nicotine dependence & 53.2 & $(45.8-60.6)$ & 37.1 & $(33.9-40.5)$ & 10.4 & $(8.5-12.5)$ & $9.93^{*}$ & $(6.7-14.6)$ & $1.84^{*}$ & $(1.3-2.6)$ \\
\hline Any illicit drug abuse/dependence & 43.7 & $(36.5-51.2)$ & 11.7 & $(9.8-13.9)$ & - & - & - & - & $6.43^{*}$ & $(4.4-9.4)$ \\
\hline \multicolumn{11}{|l|}{ Affective disarders } \\
\hline Hypomania & 2.7 & $(1.2-6,1)$ & 4.1 & $(3.0-5.7)$ & 2.5 & $(1.7-3.8)$ & 0.99 & $(0.3-2.6)$ & 0.61 & $(0.2-1.5)$ \\
\hline Single episode mania & 0.0 & $=$ & 0.2 & $(0.1-0.7)$ & 0.2 & $(0.1-0.7)$ & - & - & 0.27 & $(0.0-1.6)$ \\
\hline Bipolar I & 4.5 & $(2.5-8.1)$ & 3.0 & $(2.0-4.5)$ & 1.6 & $(1.0-2.7)$ & $244^{*}$ & $(1.0-5.8)$ & 1.39 & $(0.6-3.0)$ \\
\hline Bipolar II & 1.0 & $(0.3-4,1)$ & 0.8 & $(0.4-1.7)$ & 0.8 & $(0.4-1.8)$ & 0.84 & $(0.1-4.1)$ & 1.02 & $(0.2-4.8)$ \\
\hline MDD & 30.9 & $(24.3-38.4)$ & 23.1 & $(20.3-26.1)$ & 15.8 & $(13.6-18.3)$ & $267^{*}$ & $(1.8-4.0)$ & $1.53^{*}$ & $(1.0-2.3)$ \\
\hline Dysthymia & 7.7 & $(4.5-12.9)$ & 5.7 & $(4.4-7.5)$ & 2.5 & $(1.7-3.7)$ & $2.62^{*}$ & $(1.2-5.6)$ & 1.23 & $(0.6-2.5)$ \\
\hline Phobia NOS & 10.2 & $(6.7-15.4)$ & 6.5 & $(5.1-8.3)$ & 8.0 & $(6.4-9.9)$ & 1.46 & $(0.8-2.6)$ & $1.76^{*}$ & $(1.0-3.1)$ \\
\hline Social phobia & 10.2 & $(6.4-15.8)$ & 12.3 & $(10.1-14.9)$ & 8.5 & $(6.9-10.5)$ & 1.22 & $(0,6-2.2)$ & 0.82 & $(0.4-1.5)$ \\
\hline Specific phobia & 20.9 & $(23.6-37.2)$ & 23.7 & $(20.9-26.8)$ & 19.5 & $(17.1-22.1)$ & $1.80^{*}$ & $(1.2-27)$ & 1.31 & $(0.9-19)$ \\
\hline Generalized anxiety disorder & 11.0 & $(6.8-17.3)$ & 5.6 & $(4.2-7.5)$ & 2.9 & $(1.9-4.3)$ & $4.30^{*}$ & $(2.2-8.4)$ & $2.13^{*}$ & $(1,1-4.0)$ \\
\hline Obsesive compulsive disorder & 2.7 & $(1.1-6.5)$ & 1.4 & $(0.8-2.5)$ & 0.8 & $(0.4-1.7)$ & 2.44 & $(0.7-8.1)$ & 199 & $(0.6-6.4)$ \\
\hline Posttraumatic stress disordkr & 5.4 & $(2.9-10.0)$ & 2.5 & $(1.5-3.9)$ & 1.2 & $(0.7-2.2)$ & $4.34^{*}$ & $(1.8-10.4)$ & 2.05 & $(0.8-4.7)$ \\
\hline Any anxiety disordar & 51.3 & $(43.8-58.6)$ & 37.5 & $(34.2-40.9)$ & 31.7 & $(28.8-34.7)$ & $2.42^{*}$ & $(1.7-3.5)$ & $1.75^{*}$ & $(1.2-2.5)$ \\
\hline Somatoform disoriersisyndromes & 43.4 & $(36.2-50.9)$ & 36.9 & $(33.7-40.2)$ & 32.0 & $(20,1-35,0)$ & $1.84^{*}$ & $(1.2-2.7)$ & 1.30 & $(0.9-19)$ \\
\hline Eatüng disarders & 8.6 & $(5.2-13.8)$ & 5.3 & $(3.8-7.2)$ & 2.8 & $(1.9-4.1)$ & $3.60^{*}$ & $(1.6-8.0)$ & 1.55 & $(0.7-3.2)$ \\
\hline Steicild' ileation ${ }^{b}$ & 22.1 & $(16.4-29.0)$ & 15.3 & (13.0 17.9) & 9.5 & $(7.8-11.5)$ & $2.24^{*}$ & $(1.4-3.5)$ & 1.44 & $(0.9-2.2)$ \\
\hline \multicolumn{11}{|l|}{ Aggregute ${ }^{e}$} \\
\hline Any & 68.7 & $(61.4-75.1)$ & 55.5 & $(52.1-58.9)$ & 44.5 & $(41.4-47.7)$ & $3.06^{*}$ & $(21-4.4)$ & $1.76^{*}$ & $(1.2-2.6)$ \\
\hline 1 & 24.7 & $(19.0-31.6)$ & 25.1 & (22.2-28.3) & 22.8 & $(20.2-25.6)$ & 1.15 & $(0.7-1.7)$ & 1.00 & $(0.6-1.5)$ \\
\hline $2+$ & 43.9 & $(36.7-51.5)$ & 30.4 & $(27.3-33.7)$ & 21.8 & $(19.3-24.5)$ & $3.07^{*}$ & $(2,1-4,5)$ & $1.78^{\circ}$ & $(1.2-2.6)$ \\
\hline
\end{tabular}

$\%$ wL, indicates weighted percentages; $\mathrm{OR}$, indicates odds ratio; CI, indicates confidence interval. Percentages are computed in within the col umn totak.

\%WL., indicates weighted percen tagec, OR, indicates odds ratio; $\mathrm{Cl}$, indicates confidence interval. Perventa
a Controlled for age, gender, education, living arrangemants and financial situation at second follow-up.

a. Controlled for age, gender, education, living arrangemants and fin
Asesed as questionnaire item 'have you ever had suicidal ideas?.

a Asessed as questionnasre item 'have you ever had suicidal ideas?"

Table 3

Use of medical services and intake of medications among respondents with and without use of ecstasy and related drugs

\begin{tabular}{|c|c|c|c|c|c|c|c|c|c|c|c|c|c|}
\hline & \multirow{2}{*}{\multicolumn{3}{|c|}{$\begin{array}{l}\text { Eestasy and related drugs } \\
(N=211)\end{array}$}} & \multirow{2}{*}{\multicolumn{3}{|c|}{$\begin{array}{l}\text { Other illicit drugs } \\
(N=1008)\end{array}$}} & \multirow{2}{*}{\multicolumn{3}{|c|}{$\begin{array}{l}\text { No drug } \\
(N=1329)\end{array}$}} & \multirow{2}{*}{\multicolumn{2}{|c|}{$\begin{array}{l}\text { Associations } \\
\text { Eestasy and related } \\
\text { drugs vs, no illicit drugs }\end{array}$}} & \multirow{2}{*}{\multicolumn{2}{|c|}{$\begin{array}{l}\text { Eostasy and related drug } \\
\text { vs, other drugs }\end{array}$}} \\
\hline & & & & & & & & & & & & & \\
\hline & $N$ & $\%$ wt. & $99 \% \mathrm{CI}$ & $N$ & $\%$ wt. & $95 \% \mathrm{CI}$ & $N$ & $\% w t$. & $95 \% \mathrm{CI}$ & OR & $95 \% \mathrm{CI}$ & OR & $95 \% \mathrm{CI}$ \\
\hline \multicolumn{14}{|l|}{ Use of medical senicess ${ }^{2}$} \\
\hline General practitioner & 153 & 729 & $(65.6-79.2)$ & 741 & 72.4 & $(69.1-75.5)$ & 909 & 72.7 & $(69.8-75.5)$ & 1.05 & $(0.7-1.6)$ & 1.02 & $(0.6-1.6)$ \\
\hline Intemist & 47 & 23.6 & $(17.7-30.7)$ & 181 & 18.8 & $(16.2-21.6)$ & 234 & 19.9 & $(17.5-22.6)$ & 1.26 & $(0.8-1.9)$ & 1.35 & $(0.9-2.1)$ \\
\hline Orthopeedist & 49 & 24.8 & $(18.8-32.0)$ & 253 & 25.0 & (22.1-28.1) & 324 & 25.9 & $(23.3-28.8)$ & 0.91 & $(0.6-1.4)$ & 0.99 & $(0.6-1.5)$ \\
\hline Psychologist & 19 & 9.6 & $(6.0-15.1)$ & 70 & 7.0 & $(5.4-8.9)$ & 48 & 4.0 & $(2.9-5.5)$ & $2.30^{*}$ & $(1.1-4.5)$ & 1.36 & $(0.7-2.5)$ \\
\hline Neurologist of Psychiatrist & 11 & 4.6 & $(2.5-8.5)$ & 43 & 4.3 & $(3.1-5.9)$ & 32 & 27 & $(1.8-4.0)$ & 1.54 & $(0.6-3.5)$ & 1.03 & $(0.4-2.2)$ \\
\hline \multicolumn{14}{|l|}{ Intake of medications ${ }^{b}$} \\
\hline Pain killers & 124 & 62.5 & $(55,0-69,4)$ & 487 & 50.7 & $(47.2-54.2)$ & 567 & 48.3 & $(45.2-51.5)$ & $1.85^{*}$ & $(1.3-27)$ & $1.62^{*}$ & $(1,1-2,3)$ \\
\hline Sleeping pills & 16 & 8.0 & $(4.8-12.9)$ & 35 & 3.5 & $(2.5-5.1)$ & 23 & 1.8 & $(1.1-2.8)$ & $4.19^{*}$ & $(1.9-9.2)$ & $2.21^{*}$ & $(1.1-4.4)$ \\
\hline Sedatives & 17 & 10.1 & $(6.1-16.3)$ & 52 & 6.1 & $(4.6-8.2)$ & 51 & 4.5 & $(3.3-6.2)$ & $2.32^{*}$ & $(1.2-4.6)$ & 1.68 & $(0.8-3.2)$ \\
\hline Psychotropies & 16 & 7.5 & $(4.4-12.4)$ & 22 & 2.3 & $(1.5-3.6)$ & 11 & 0.8 & $(0.4-1.5)$ & $9.01^{*}$ & $(3.7-21.9)$ & $3.28^{*}$ & $(1.6-6.7)$ \\
\hline Stimulants & 13 & 6.5 & $(3.7-11.4)$ & 15 & 1.3 & $(0.7-2.2)$ & 10 & 0.9 & $(0.4-1.7)$ & $6.70^{*}$ & $(2.4-18.4)$ & $4.88^{*}$ & $(2,1-11,0)$ \\
\hline Other medicines & 83 & 39.9 & $(32.8-47.6)$ & 380 & 37.1 & $(33.840 .5)$ & 482 & 38.5 & $(35.5-41.6)$ & 1.07 & $(0.7-1.6)$ & 1.11 & $(0.7-1.6)$ \\
\hline
\end{tabular}

\%wL. indicates weighted percentages; $\mathrm{Cl}$ indicates confidence interval and $\mathrm{OR}$ odds ratio; $\mathrm{ORs}$ are con trolled for age, gender, education, living arrangements and financial situation, ${ }^{*}, P<0.05$.

${ }^{2}$ Use of medical services during the last 12 months

b Intake of medications during the last 4 weeks. 
Table 4

Temporal ordering of age of first uxe of ecstasy and related drugs compared with age of onset of DSM-IV mental disorders among adolescents with hifetime ecstasy use and comorbid DSM-IV mental disorders

\begin{tabular}{|c|c|c|c|c|c|c|}
\hline \multirow[t]{3}{*}{ DSM-IV disorders ${ }^{\mathrm{n}}$} & \multicolumn{6}{|c|}{$\begin{array}{l}\text { Proportions (\%w) of persons with lifet ime ecstasy use and comorbid DSM-IV mental disorders who report first } \\
\text { use of ecstasy/related drugs... }\end{array}$} \\
\hline & \multicolumn{2}{|c|}{ Temporally primary } & \multicolumn{2}{|c|}{ In the same year } & \multicolumn{2}{|c|}{ Temporally secondary } \\
\hline & $\%$ wt. & $95 \% \mathrm{CI}$ & $\%$ wt. & $99 \% \mathrm{CI}$ & \%wt. & $99 \% \mathrm{CI}$ \\
\hline \multicolumn{7}{|l|}{ Substance use disarders } \\
\hline Alcohol abuse or dependence & 11.1 & $(6.3-18.8)$ & 10.9 & $(6.1-18.9)$ & 78.0 & $(68.6-85.2)$ \\
\hline Nicotine dependence & 15.9 & $(9.6-25.2)$ & 9.3 & $(5.0-16.5)$ & 74.9 & $(64.8-82.8)$ \\
\hline Ilicit drugs abuse or dependence & 25.5 & $(16.1-37.9)$ & 31.6 & $(21.8-43.3)$ & 42.9 & $(32.0-54.6)$ \\
\hline \multicolumn{7}{|l|}{ Affective diwnders } \\
\hline MDD & 40.0 & $(26.5-55.2)$ & 15.5 & $(8.3-27.3)$ & 4.5 & $(30.3-99.5)$ \\
\hline Dysthymia & 5.5 & $(0.6-36.7)$ & 25.1 & $(8.1-56.0)$ & 69.3 & $(39.1-88.9)$ \\
\hline Any affective disorder & 33,4 & $(22.4-46.5)$ & 13.8 & $(7.6-23.9)$ & $\$ 2.8$ & $(40.1-65.2)$ \\
\hline \multicolumn{7}{|l|}{ Anxiety disonders } \\
\hline Panic disorder & 22.9 & $(4.1-67.2)$ & 16,0 & $(2.8-55.5)$ & 61.2 & $(24.0-88.7)$ \\
\hline Agor aphobia w/o Panic disorder & 25.7 & $(3.9-74.6)$ & 11.4 & $(0.8-66.6)$ & 63.0 & $(19.3-92.4)$ \\
\hline Phobia Nos & 29.8 & $(11.0-59.4)$ & 15,4 & $(4.4-41.6)$ & 54.8 & $(29.7-77.6)$ \\
\hline Social phobia & 19.4 & $(5.5-49.9)$ & 4.0 & $(0.5-27.9)$ & 76.6 & $(47.5-92.2)$ \\
\hline Specific phobia & 1.6 & $(0.2-11.2)$ & - & - & 98.4 & $(88.8-99.8)$ \\
\hline General bed anxiety disorder & 25.3 & $(9.3-52.8)$ & - & - & 74.7 & $(47.2-90.7)$ \\
\hline Obessive compulsive disorder & 16,0 & $(0.8-81.9)$ & 32.1 & $(3,4-86,5)$ & $\$ 2.0$ & $(7.5-93.5)$ \\
\hline Posttraumatic stress disorder & 16.0 & $(2.9-55.2)$ & 28.1 & $(7.7-64.6)$ & $\$ 5.9$ & $(22.1-85.1)$ \\
\hline Any anxiety disorder & 11.3 & $(5.9-20.7)$ & 6.4 & $(3.0-13.1)$ & 82.3 & $(72.5-89.1)$ \\
\hline Any somatofarm disonderisyndrome & 17.7 & $(10.3-28.8)$ & 9.1 & $(4.4-18.1)$ & 73.2 & $(61.5-82.3)$ \\
\hline Any eating disonder & 28.5 & $(10.0-58.7)$ & 5.6 & $(0.6-36.4)$ & 65.9 & $(36,8-86,6)$ \\
\hline \multicolumn{7}{|l|}{ Aggregute } \\
\hline Any of the above & 6.7 & $(3,6-12.0)$ & 4.9 & $(2,5-9.3)$ & 88.4 & $(82.492 .6)$ \\
\hline \multicolumn{7}{|l|}{ Any of the above, } \\
\hline
\end{tabular}

CI indicates confidence interval; NOS not otherwise specified. \%wt. indicates weighted percentages. Percentages are computed on the row total. a Cumulated lifetime incidence at second follow-up.

\section{Acknowledgements}

This work is part of the Early Developmental Stages of Psychopathology (EDSP) Study and is funded by the German Ministry of Research and Technology, project no. 01 EB 9405/6 and 01 EB 9901/6. Principal investigators are Dr Hans-Ulrich Wittchen (PI) and Dr Roselind Lieb (Co-PI). Current or former staff members of the EDSP group are Dr Kirsten von Sydow, Dr Gabriele Lachner, Dr Axel Perkonigg, Dipl.-Psych. Peter Schuster, Dr Franz Gander, Dipl.-Stat. Michael Höfler and Dipl.-Psych. Holger Sonntag as well as Dipl.-Psych. Esther Beloch, Mag. phil. Martina Fuetsch, Dipl.-Psych. Elzbieta Garczynski, Dipl.-Psych. Alexandra Holly, Dipl.-Psych. Barbara Isensee, Dipl.- Psych. Marianne Mastaler, Dr Chris Nelson, Dipl.-Inf. Hildegard Pfister, Dr Victoria Reed, Dipl.-Psych. Dilek Türk, Dipl.-Psych. Antonia Vossen, Dr Ursula Wunderlich and Dipl.-Psych. Petra Zimmermann. Scientific advisors are Dr Jules Angst (Zurich), Dr Jürgen Margraf (Basel), Dr Günther Esser (Potsdam), Dr Kathleen Merikangas (Yale, New Haven) and Dr Ron Kessler (Harvard, Boston). The authors wish to thank Dr Renee Goodwin for suggestions on language used in this paper. Our special thanks go to the participants of the study.

\section{References}

- $\quad$ Allan, R.P., McCann, U.D., Ricaurte, G.A., 1993. Persistent effects of (+/-)3,4methylenedioxymethamphetamine (MDMA, 'Ecstacy') on human sleep. Sleep 16 (6), 560-564.

- APA (American Psychiatric Association), 1994. Diagnostic and statistical manual of mental disorders, fourth ed., APA, Washington, DC.

- Beck, J., Rosenbaum, M., 1994. Pursuit of Ecstasy: the MDMA Experience. State University of New York Press, Albany. 
- Chesher, G., 1990. Designer drugs - the 'whats' and the 'whys'. Med. J. Aust. 153 (3), 157-161.

- Christophersen, A.S., 2000. Amphetamine designer drugs - an overview and epidemiology. Toxicol. Lett. 15 (112-113), 127-131.

- Galliot-Guilley, M., Sueur, C., Lebeau, B., Fompeydie, D., Benezech, A., Bazard, J.P., 1999. Ecstasy and its 'counterparts'. Presse Med. 28 (7), 358-362.

- Gouzoulis-Mayfrank, E., Hermle, L., 1994. Die Gefahren von Ecstasy. Nervenarzt 64, 478-480.

- Höfler, M., Lieb, R., Perkonigg, A., Schuster, P., Sonntag, H., Wittchen, H.-U., 1999. Covariates of cannabis use progression in a representative population sample of adolescents: a prospective examination of vulnerability and risk factors. Addiction 94 (11), 1679-1694.

- Jansen, K.L., 1999. Ecstasy (MDMA) dependence. Drug Alcohol Depend. 53, 121-124.

- Krystal, J.H., Price, L.H., Opsahl, C., Ricuarte, G.A., Heninger, G.R., 1992. Chronic 3,4methylenedioxymethamphetamine (MDMA) use: effects on mood and neuropsychological function. Am. J. Drug Alcohol Abuse 18 (3), 331-341.

- Lachner, G., Wittchen, H.-U., Perkonigg, A., Holly, A., Schuster, P., Wunderlich, U., Türk, D., Garczynski, E., Pfister, H., 1998. Structure, content and reliability of the munich-composite international diagnostic interview (M-CIDI). Substance use sections. Eur. Addict. Res. 4 (1-2), 28-41.

- Lieb, R., Isensee, B., von Sydow, K., Wittchen, H.-U. 2000. The early developmental stages of psychopathology study (EDSP): I. Methodology - an update. Eur. Addict. Res. 6 (4) $170-182$.

- Liester, M.B., Grob, C.S., Bravo, G.L., Walsh, R.N., 1992. Phenomenology and sequelae of 3,4-methylenedioxymethamphetamine use. J. Nerv. Ment. Dis. 180 (6), 345-352.

- McCann, D.U., Ridenour, A., Shaham, Y., Ricaurte, G.A., 1994. Serotonin neurotoxicity after (+/-)3,4-methylenedioxymethamphetamine (MDMA; 'Ecstasy'): a controlled study in humans. Neuropsychopharmacology 10 (2), 129-138.

- McCann, U.D., Eligulashvili, V., Ricaurte, G.A., 2000. 3,4methylenedioxymethamphetamine ('Ecstasy') induced serotonin neurotoxicity: clinical studies. Neuropsychobiology 42 (1), 11-16.

- McCullagh, P., Nelder, F., 1989. Generalized Linear Models, second ed.. Chapman \& Hall, London.

- Morgan, M.J., 1998. Recreational use of 'Ecstasy' is associated with elevated impulsivity. Neuropsychopharmacology 19 (4), 252-264.

- $\quad$ Parrott, A.C., Lees, A., Garnham, N.J., Jones, M., Wesnes, K., 1998. Cognitive performance in recreational users of MDMA of 'ecstacy': evidence for memory deficits. J. Psychopharmacol. 12, 79-83.

- Pederson, W., Skrondal, A., 1999. Ecstasy and new pattern of drug use: a normal population study. Addiction 94 (11), 1695-1706.

- Perkonigg, A., Lieb, R., Wittchen, H.-U., 1998a. Prevalence of use, abuse and dependence of illicit drugs among adolescents and young adults in a community sample. Eur. Addict. Res. 4 (1-2), 58-66.

- Perkonigg, A., Lieb, R., Wittchen, H.-U., 1998b. Substance use, abuse and dependence in Germany: a review of selected epidemiological data. Eur. Addict. Res. 4 (1-2), 8 -17.

- Perkonigg, A., Lieb, R., Höfler, M., Schuster, P., Sonntag, H., Wittchen, H.-U., 1999. Patterns of cannabis use, abuse and dependence over time: incidence, progression and stability in a sample of 1228 adolescents. Addiction 94 (11), 1663-1678.

- $\quad$ Reed, V., Gander, F., Pfister, H., Steiger, A., Sonntag, H., Trenkwalder, C., Hundt, W., Wittchen, H.-U., 1998. To what degree the composite international diagnostic interview (CIDI) correctly identifies DSM-IV disorders? Testing validity issues in a clinical sample. Int. J. Meth. Psychiatr. Res. 7 (3), 142-155.

- Ricaurte, G.A., Byron, G., Strauss, L., Seiden, L., Schuster, C., 1985. Hallucinogenic amphetamine selectively destroys brain serotonin nerve terminals. Science 229, 986-988. 
- $\quad$ Ricaurte, G.A., Forno, L.S., Wilson, L.E., DeLanney, L.E., Irwin, I., Molliver, M.E., Langston, J.W., 1988. (+/-)3,4-Methylenedioxymethamphetamine (MDMA) on central serotonergic neurons in nonhuman primates: neurochemical observations. J. Pharm. Exp. Ther. 261 (2), 616-622.

- $\quad$ Ricaurte, G.A., Yuan, J., McCann, U.D., 2000. 3,4-methylenedioxymethamphetamine ('ecstasy') induced serotonin neurotoxicity: studies in animals. Neuropsychobiology 42 (1), 5-10.

- Royall, R.M., 1986. Model robust confidence intervals using maximum likelihood estimators. Int. Statist. Rev. 54, 221-226.

- Scheffel, U., Szabo, Z., Mathews, W.B., Finley, P.A., Dannals, R.F., Ravert, H.T., Szabo, K., Yuan, J., Ricaurte, G.A., 1998. In vivo detection of short- and long-term MDMA neurotoxicity-a positron emission tomography study in the living baboon brain. Synapse 29 (2), 183-192.

- $\quad$ Schifano, F., DiFuria, L., Forza, G., Minicuci, N., Bricolo, R., Morgan, M.J., 1998. MDMA ('ecstasy') consumption in the context of polydrug abuse: a report on 150 patients. Drug Alcohol Dep. 52, 85-90.

- Schuster, P., Lieb, R., Lamertz, C., Wittchen, H.-U., 1998. Is the use of ecstasy and hallucinogens increasing? Results from a community study. Eur. Addict. Res. 4 (1-2), 7582.

- Schütz, C.G., Soyka, M., 1998. Halluzinogene, einschließlich Ecstasy, PCP und Anticholinergika. In: M. Soyka (Ed.), Drogen- und Medikamentenabhängigkeit, Stuttgart: Wiss. Verl.-Ges.

- Sherlock, K., Wolff, K., Hay, A.W., Conner, M., 1999. Analysis of illicit ecstasy tablets: implications for clinical management in the accident and emergency department. J. Accid. Emerg. Med. 16, 194-197.

- Solowij, N., Hall, W., Lee, N., 1992. Recreational MDMA use in Sydney: a profile of 'ecstasy' users and their experiences with the drug. Br. J. Addict. 87, 1161-1172.

- Sprague, J.E., Everman, S.L., Nichols, D.E., 1998. An integrated hypothesis for the serotonergic axonal loss induced by 3,4-methylenedioxymethamphetamine.

Neurotoxicology 19 (3), 427-441.

- StataCorp. 1999. STATA STATISTICAL Software: Release 6.0., Stata Corporation, College Station, TX.

- Sydow, K., von, Lieb, R., Pfister, H., Höfler, M., Wittchen, H.-U. 2002. Use, abuse and dependence of ecstasy and related drugs in adolescents and young adults - a transient phenomenon? Results from a longitudinal community study. Drug Alcohol Dep. 66, 147159.

- $\quad$ Thomasius, R., Schmolke, M., Kraus, D., 1997. MDMA ('ecstasy') use-an overview of psychiatric and medical sequelae. Fortschr. Neurol. Psychiatr. 65 (2), 49-61.

- Topp, L., Hando, J., Dillon, P., Roche, A., Solowij, N., 1999. Ecstasy use in Australia: patterns of use and associated harm. Drug Alcohol Depend. 55, 105-115.

- Vollenweider, F.X., Gamma, A., Liechti, M., Huber, T., 1998. Psychological and cardiovascular effects and short-term sequelae of MDMA ('ecstasy') in MDMA-native healthy volunteers. Neuropsychopharmacology 19 (4), 241-251.

- Wittchen, H.-U., Pfister, H. (Eds.). 1997. DIA-X-Interviews: Manual für ScreeningVerfahren und Interview; Interviewheft Längsschnittuntersuchung (DIA-X-Lifetime); Ergänzungsheft (DIA-X-Lifetime); Interviewheft Querschnittuntersuchung (DIA-X-12 Monate); Ergänzungsheft (DIA-X-12 Monate); PC-Programm zur Durchführung des Interviews (Längs- und Querschnittuntersuchung); Auswertungsprogramm, Swets \& Zeitlinger, Frankfurt.

- Wittchen, H.-U., Perkonigg, A., Lachner, G., Nelson, C.B., 1998a. Early developmental stages of psychopathology study (EDSP): objectives and design. Eur. Addict. Res. 4 (1-2), 18-27.

- $\quad$ Wittchen, H.-U., Nelson, G.B., Lachner, G., 1998b. Prevalence of mental disorders and psychosocial impairments in adolescents and young adults. Psychol. Med. 28, 109-126. 
- Wittchen, H.-U., Lachner, G., Wunderlich, U., Pfister, H., 1998c. Test-retest reliability of the computerized DSM-IV version of the munich composite international diagnostic interview (M-CIDI). Soc. Psychiatry Psychiatr. Epidemiol. 33, 568-578.

- Wittchen, H.-U., Lieb, R., Schuster, P., Oldehinkel, T., 1999. When is onset? Investigations into early developmental stages of anxiety and depressive disorders. In: Rapoport, J.L. (Ed.), Childhood Onset Of Adult Psychopathology Clinical And Research Advances. American Psychiatric Press, Washington, pp. 259-302.

- Wodarz, N., Böning, J., 1993. ‘Ecstasy'-induziertes psychotisches depersonalisationssyndrom. Nervenarzt 64, 478-480.

- World Health Organization, 1990. The Composite International Diagnostic Interview (CIDI), World Health Organization, Geneva.

- World Health Organization, 1994. International Classification of Diseases, 10th revision, World Health Organization, Division of Mental Health, Geneva.

- World Health Organization, 1996. Worldwide amphetamine abuse - 'a particular concern for WHO', World Health Organization press release WHO/77 Rev., 13 November 1996, World Health Organization Geneva. 